\title{
Design and Analysis of a Thinned Phased Array Antenna for 5G Wireless Applications
}

\author{
Cheon-Bong Moon $\mathbb{D}^{D}$, Jin-Woo Jeong, Kyu-Hyun Nam $\mathbb{D}^{\mathbb{D}}$, Zhou Xu $\mathbb{D}^{\mathbb{D}}$, and Jun-Seok Park ${ }^{\circ}$ \\ Department of Electronics Engineering, Kookmin University, Seoul 02707, Republic of Korea \\ Correspondence should be addressed to Cheon-Bong Moon; moonceo@kookmin.ac.kr
}

Received 17 June 2021; Revised 29 August 2021; Accepted 6 October 2021; Published 21 October 2021

Academic Editor: Seong-Youp Suh

Copyright (c) 2021 Cheon-Bong Moon et al. This is an open access article distributed under the Creative Commons Attribution License, which permits unrestricted use, distribution, and reproduction in any medium, provided the original work is properly cited.

\begin{abstract}
This paper focuses on the design of a thinned array antenna using microstrip patch, which is a novel task in recent years. The aim of thinned array antenna synthesis is to obtain a desired radiation pattern with a minimum number of antenna elements. For uniform spacing array antenna, a certain number of elements can be removed, while maintaining a desired radiation pattern using genetic algorithm optimization. Parameters such as beamwidth and side lobe level are evaluated for proposed thinned array antenna by comparison with those obtained for different types of uniform array antennas. Numerical examples are presented to show the high energy efficiency of the proposed thinned array antenna.
\end{abstract}

\section{Introduction}

Technology and science have made major changes to the way we live, with the development of high-tech, scientific challenges and changes come along with it. Fifth generation (5G) mobile communication brings faster speed, high data rate, and larger bandwidth meeting the current demand of the wireless technology. Antenna plays an important role in such communication system, and its radiation characteristic affects the overall system. The microstrip patch antenna is widely used in varies communication systems; it is attractive due to its thinned profile and light weight, being simple to manufacture, being easily integrated with circuit, its low cost, etc.

Array antenna consists of two or more antenna elements; the research on uniform distribution array antenna is very mature, in which the spacing between adjacent antenna elements is the same and there are the same number of antenna elements along each line. However, the report of nonuniform array antenna design using microstrip patch antenna is difficult to find.

A large-scale uniform distributed array antenna is complex to build and increases manufactured cost, and it occupies large area. Therefore, eliminating antenna from the array, to be formed as thinned array, would be a wise choice, while maintaining the desired gain and suppressing side lobe level.

The research on thinned array received extensive concern in communication engineering in recent years; relative papers provide useful results [1-16]. But, most of these researches study thinned array antenna based on the assumption of no coupling effect which occurs between antenna elements and using infinitesimal point to represent antenna radiator. However, in practice, mutual coupling has effect on radiation pattern and could cause pattern, beamwidth, and gain deviation [17], and in the case of microstrip patch antenna, the patch width may be longer than the half wavelength, so it could not be realized if the minimum spacing is set to half wavelength as designed in many researches $[3,4]$. Up to now, there is no published work that researches on the actual design of thinned array antenna, let along thinned array antenna for $5 \mathrm{G}$ wireless system. So, in this research, the thinned array antenna using microstrip patch antenna is designed, and the designed 34 elements thinned array is evaluated by compared with different types of uniform array antennas, based on the full-wave simulator HFSS. To reduce the manufactured cost of PCB, the thinned array antenna is designed on the low-cost Fr-4 substrate in 
which the thickness is $0.2 \mathrm{~mm}$, dielectric constant is 4.2 , and the loss tangent is 0.02 ; then, the proposed thinned array antenna is finally fabricated and measured to verify the theoretical expectation.

\section{Corporate-Feed Network and Uniform Array Antenna Design}

Before analyzing the thinned array antenna, let us first design uniform array, because the thinned array antenna is obtained based on the uniform array antenna. Moreover, the designed uniform array antennas could be compared with thinned array antenna later to observe the radiation pattern characteristic improvement of thinned array antenna.

Before designing the uniform array antenna, the corporate-feed network would be analyzed first. The corporatefeed network is usually the power divider/combiner; in this case, the designed TX array antennas do not need high isolation property, thus the T-junction power divider is chosen, as shown in Figure 1(a).

Then, the substrate material and the thickness must be chosen to design the array antenna. To reduce the manufactured cost, the Fr-4 substrate is an appealing option. As for the substrate thickness, it is needed to trade off the relationship among the antenna efficiency and gain, and another important aspect, higher order mode existence, as the single-mode operation is wanted for microstrip. Through the simulation, the second order mode has the cut-off frequency above the $30 \mathrm{GHz}$ for Fr-4 substrate with the dielectric constant of 4.2 and thickness of $0.2 \mathrm{~mm}$; considering the gain and efficiency value are satisfactory, the substrate with that specification is chosen.

To compensate the parasitic reactance at the junction, the notch is added for power divider, as shown in Figure 1(a) [18], and then an 8-way power divider is designed, in which the $50 \Omega$ microstrip width $W_{1}$ is $0.37 \mathrm{~mm}$ and the spacing of adjacent output ports is about $4 \mathrm{~mm}$. Through the optimization simulation, the appropriate dimension parameters are found when $17 \mu \mathrm{m}$ thickness of copper is used, and the values of $\mathrm{W}_{2}, \mathrm{~W}_{3}$, and $\mathrm{L}_{1}$, as described in Figure 1(b), are different in three stages for designed 8-way power divider; the values are $0.2,0.25$, and 1.28 , respectively, for first stage, $0.21,0.15$, and 1.08 for second stage, and $0.1,0.19$, and 1 for third stage, where the units are all in millimeter.

The antenna element dimension would be calculated next, based on the reference and mass of simulation experiments, when the patch length and width, $\mathrm{L}_{4}$ and $\mathrm{W}_{5}$, as illustrated in Figure 2, are $2.55 \mathrm{~mm}$ and $3.2 \mathrm{~mm}$, it has the resonant frequency at $28 \mathrm{Ghz}$.

Finally, the impedance matching work must be done which highly affects the return loss of the whole array system. Generally, a quarter-wavelength microstrip impedance transformer can be used, but it is found that the width of $\lambda / 4$ microstrip impedance transformer would have the width over $6 \mathrm{~mm}$, which is difficult to be realized in dense array system. Hence, a patch, in which the length $\left(\mathrm{L}_{3}\right)$ is equal to antenna element length $\left(\mathrm{L}_{4}\right)$, is used for matching to $50 \Omega$, although the added patch can radiate electromagnetic wave; due to its shorter width, the effect of its radiation can be ignored.

Microstrip patch antenna usually has the maximum gain toward the upward direction of the substrate, thus the broadside array can make full use of radiated energy. In broadside array, each antenna element must have the same excitation phase, and the spacing between adjacent antenna elements can be any value [19]. Because the patch antenna length is approximately equal to half wavelength, the microstrip length $\mathrm{L}_{5}$, as illustrated in Figure 2, is set equal to $\mathrm{L}_{4}$, and then all antenna elements can be excited in the same phase. In addition, the optimized value of $\mathrm{L}_{2}$ in Figure 2 could be equal to $\mathrm{L}_{4}$.

Based on the theories and methods discussed above, an $8 \times 4$ broadside uniform array antenna is designed in HFSS, as shown in Figure 3(a). The optimized value of $\mathrm{W}_{4}$ in Figure 2 is about $1.27 \mathrm{~mm}$; the substrate size is $40 \times 60 \mathrm{~mm}$. The simulated return loss $\left(\mathrm{S}_{11}\right)$ and VSWR are shown in Figure 4. It has return loss of $-31 \mathrm{~dB}$ and VSWR of 1.03 at $28 \mathrm{Ghz}$, which demonstrate the array antenna operates well at mentioned frequency.

Then, an $8 \times 8$ broadside uniform array antenna is designed, as shown in Figure 3(b). The optimized value of $\mathrm{W}_{4}$ is about $0.85 \mathrm{~mm}$; the substrate size is $40 \times 60 \mathrm{~mm}$. The simulated results are shown in Figure 5. The designed array has return loss of $-27 \mathrm{~dB}$ and VSWR of 1.05 at $28 \mathrm{Ghz}$, which can prove the designed array antenna works well at that frequency.

\section{Thinned Array Antenna Design}

3.1. 34 Elements Thinned Array Antenna. In the case of a uniform array of identical isotropic antenna elements with equal excitation amplitude and fixed progressive difference of excitation phase, the radiation field can be obtained by multiplying the array factor by the field of a single antenna element at the reference point [19]. Hence, the radiation pattern is closely related to the array factor for an array system.

Then, let the array factor be multiplied by a matrix $f_{\mathrm{mn}}$; when the antenna element is removed, the $f_{m n}=0$; otherwise, $f_{\mathrm{mn}}=1$. Then, the total number of thinned array antenna elements would be equal to

$$
\text { total antenna element number }=\sum_{m=1}^{M} \sum_{n=1}^{N} f_{m n}
$$

where $M$ and $N$ are the total number of lines in two dimensions, respectively, and then the thinned array factor could be expressed as

$$
\mathrm{AF}=\sum_{m=1}^{M} \sum_{n=1}^{N} e^{j 2 \pi / \lambda\left[\left(d_{x}\right)_{m n} \sin (\theta) \sin (\varphi)+\left(d_{y}\right)_{m n} \sin (\theta) \cos (\varphi)\right]} \times f_{m n},
$$

where $\left(d_{x}\right)_{m n}$ and $\left(d_{y}\right)_{m n}$ are the distance from a reference point along two dimensions, respectively. The fitness function could be set to the sum of the maximum side lobe levels (SLL) of E-plane and H-plane. 


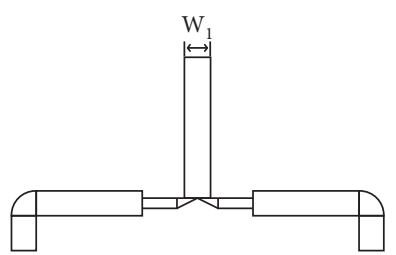

(a)

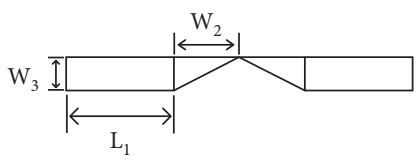

(b)

FIgURE 1: (a) Microstrip T-junction power divider with notch; (b) structure dimension of $\lambda / 4$ microstrip impedance transformer.

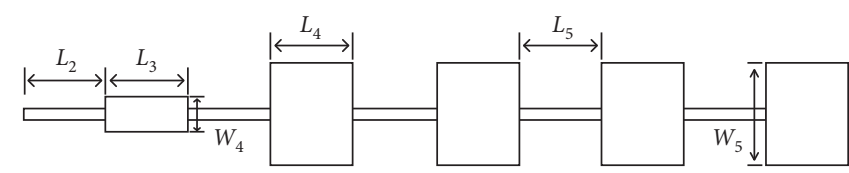

FIGURE 2: Dimension of linear array antenna.

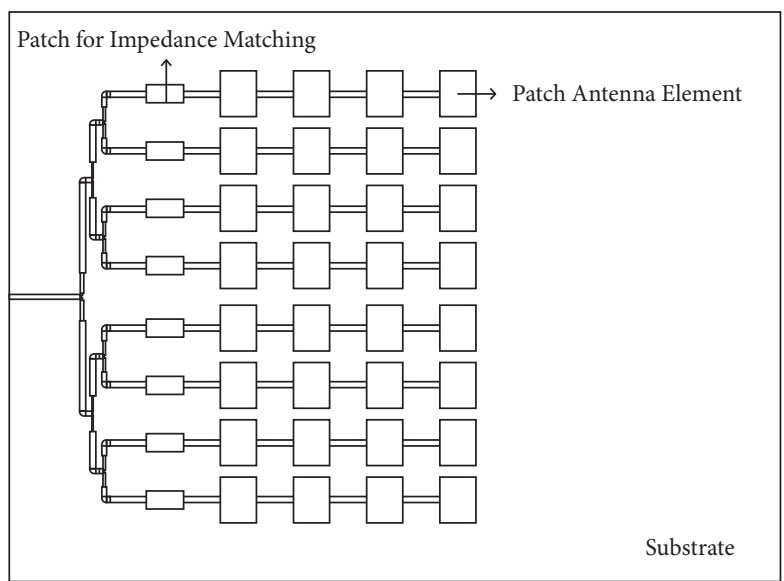

(a)

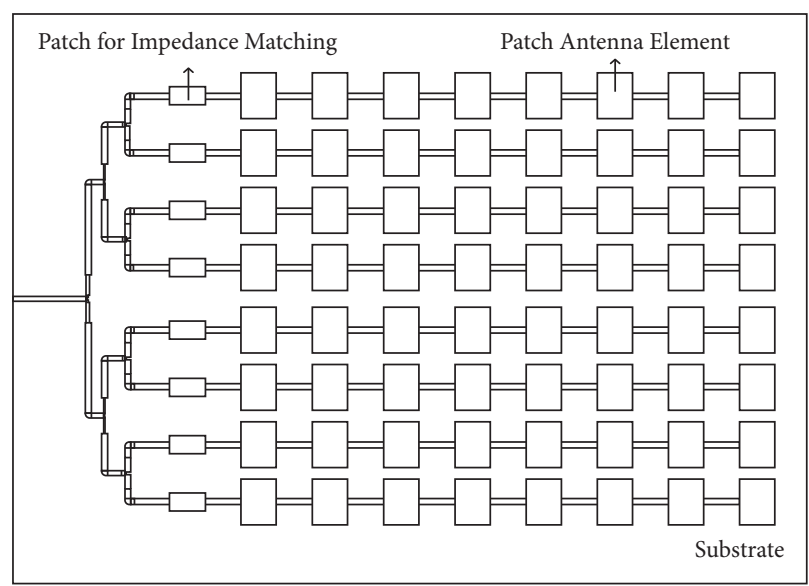

(b)

FIGURE 3: Designed $8 \times 4$ (a) and $8 \times 8$ (b) broadside uniform array antenna models in HFSS.

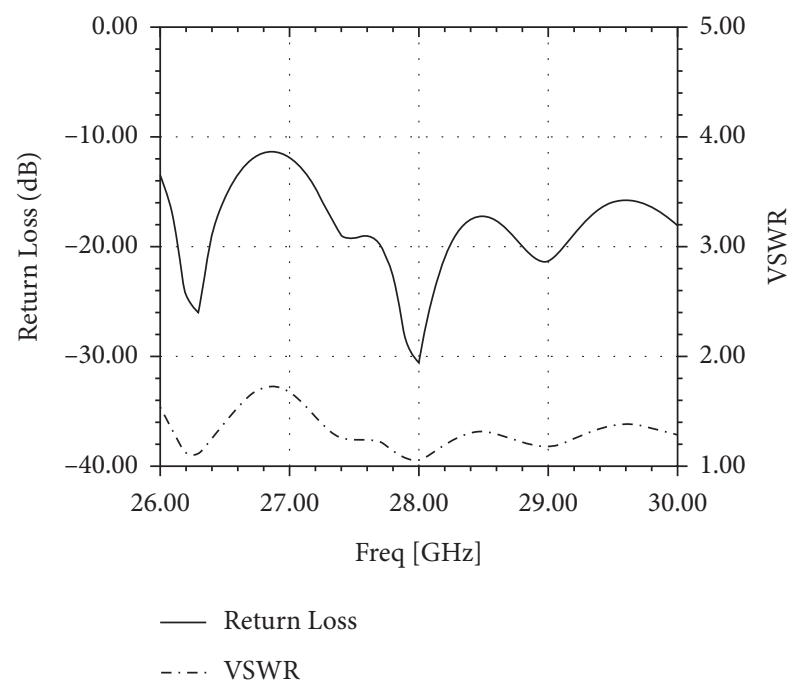

FIgURE 4: Designed $8 \times 4$ broadside uniform array antenna simulation results of return loss (S11) and VSWR.

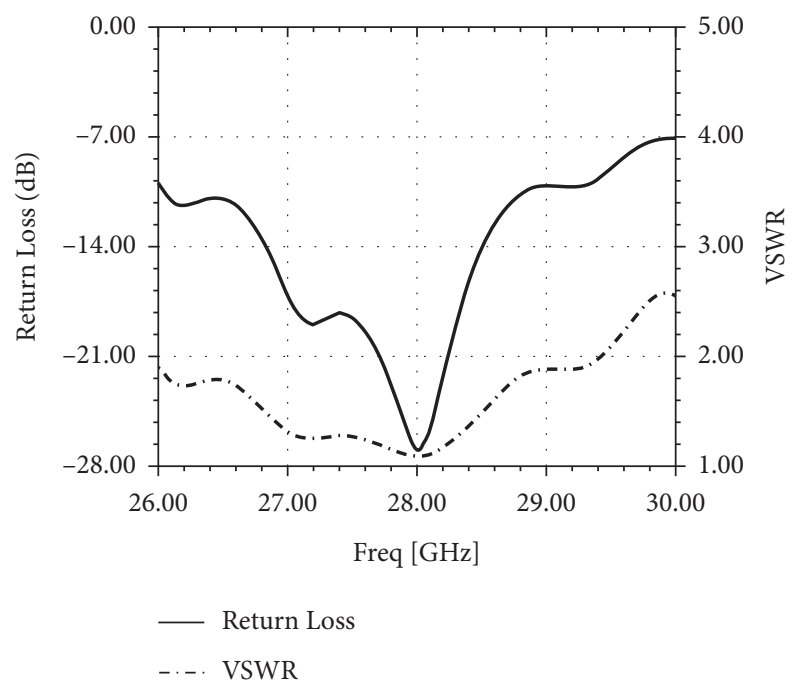

FIgURE 5: Designed $8 \times 8$ broadside uniform array antenna simulation results of return loss (S11) and VSWR. 


$$
\mathrm{SLL}=\max _{\theta \in S 1, \varphi=0^{\circ} / 90^{\circ}} \operatorname{AF}(\theta, \varphi),
$$

where $S 1=\left\{\phi \mid-\pi \leq \phi \leq-\phi_{o} \cup \phi_{o} \leq \phi \leq \pi\right\}$, where $\phi_{o}$ is the angular of the first null.

$$
\text { Fitness function }=\left.\operatorname{SSL}\right|_{\varphi=0^{\circ}}+\left.\operatorname{SSL}\right|_{\varphi=90^{\circ}} .
$$

The optimization work is to find the lowest fitness function, and the genetic algorithm (GA) is a useful tool for such work.

However, the optimized thinned array may not show good performance in EM simulation, some optimized thinned array antennas have too small gains, and some have large side lobe; it could be affected by the mutual coupling between antenna elements and other reasons.

Through a lot of program simulations and electromagnetic (EM) simulations, a thinned array consisting of 32 elements is found to have the best radiation performance in EM simulation, and 2 antenna elements within the feeding network are added to enhance the gain, and it is found that the side lobes are also suppressed after they are added, and the normalized radiation pattern results of 34 elements thinned array antenna, calculated by MATLAB, are shown in Figure 6.

The 34 elements thinned array antenna can be realized for removing undesired antenna elements from the $8 \times 8$ broadside uniform array antenna discussed in previous section, and then the remained antenna elements are connected with microstrip line, as shown in Figure 7. Because the antenna element length $\left(\mathrm{L}_{4}\right)$ and the microstrip line length between adjacent antenna elements $\left(\mathrm{L}_{5}\right)$ are same to half wavelength, hence the excited phase of remained antenna could be increased by $2 n \pi(n=0,1,2, \ldots)$, and then it can still be ensured that all the antenna elements can be inphase excited, therefore the thinned array antenna is still a broadside array antenna. The optimized value of $\mathrm{W}_{4}$ is $1.27 \mathrm{~mm}$; the substrate size is $40 \times 60 \mathrm{~mm}$. The return loss and the VSWR simulation results are shown in Figure 8 and the radiation pattern in E-plane and $\mathrm{H}$-plane are shown in Figure 9. The gain is $13.6 \mathrm{dBi}$, and the return loss of $-28 \mathrm{~dB}$ and VSWR of 1.03 indicate the proposed 34 elements thinned array antenna is matched well at operating frequency.

In order to prove the side lobes are effectively suppressed for proposed 34 elements thinned array antenna, the radiation pattern of E-plane and $\mathrm{H}$-plane is compared with the $8 \times 8$ broadside uniform array antenna mentioned above, as illustrated in Figure 10. It is apparent from the figures that the thinned array antenna shows better side lobe suppression, though the gain is just $1 \mathrm{dBi}$ lower than the $8 \times 8$ uniform array antenna. The maximum side lobe (MSL) of 34 elements thinned array antenna is $0.4 \mathrm{dBi}$ and $0.7 \mathrm{dBi}$ in E-plane and $\mathrm{H}$-plane, respectively; they are $3.1 \mathrm{dBi}$ and $5.7 \mathrm{dBi}$ lower than the $8 \times 8$ uniform array antenna in E-plane and $\mathrm{H}$-plane, respectively.

Then, the radiation pattern of proposed 34 elements thinned array antenna is also compared with the $8 \times 4$ broadside uniform array antenna designed before, as illustrated in Figure 11. The gain is about $1.2 \mathrm{dBi}$ higher than

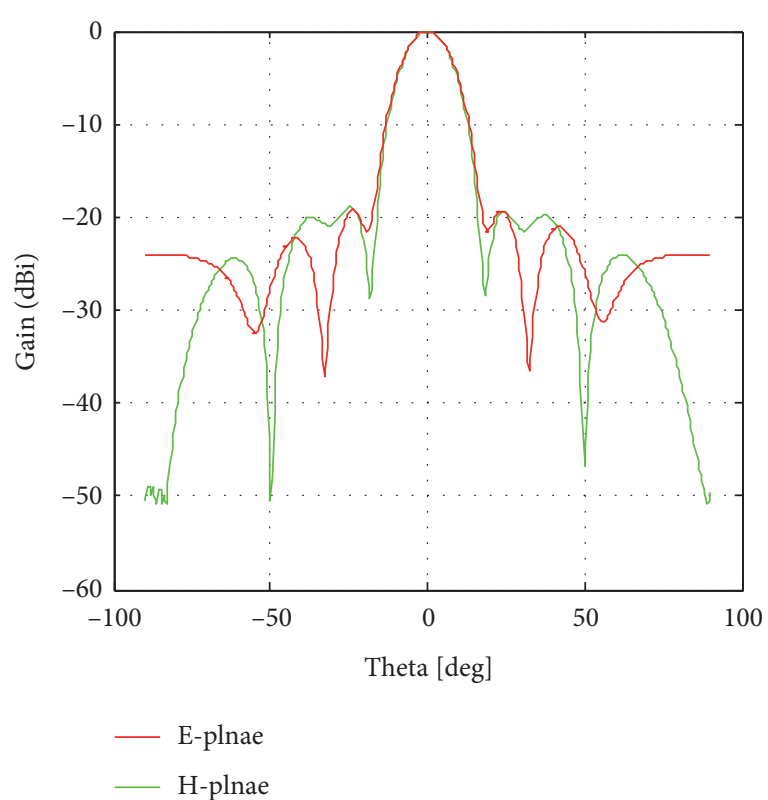

FIGURE 6: Normalized radiation pattern of proposed 34 elements thinned array antenna in E-plane and H-plane in MATLAB.

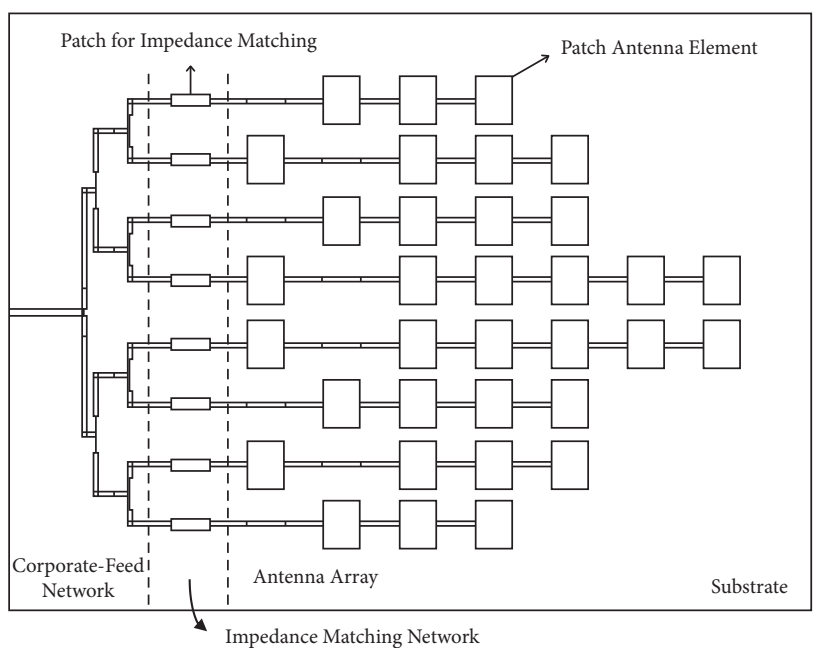

Figure 7: Proposed 34 elements thinned array antenna dimension.

the uniform array antenna and the MSL are $4.4 \mathrm{dBi}$ lower in $\mathrm{H}$-plane, though the MSL is just $0.5 \mathrm{dBi}$ higher in E-plane.

The proposed 34 elements thinned array antenna beamforming characteristic is shown in Figure 12; it is capable of beam scanning at the range of $-40^{\circ} \sim 40^{\circ}$ from upward direction of array antenna in $\mathrm{H}$-plane where $3 \mathrm{dBi}$ is considered as reference. To set progressive phase difference between each linear antenna array line, 8 ports are added in the front of each linear antenna array line, as shown in Figure 13. The gain shown in Figure 12 is slightly higher than that of Figure 9; it is because the loss exists through the corporate-feed network. As the phase shifter researched in our laboratory has resolution of $5.6^{\circ}$, thus the beam pattern is observed when the progressive phase difference is changed in $5.6^{\circ}$-step; the results show that the beam direction is changed in $2.4^{\circ}$-step approximately. 


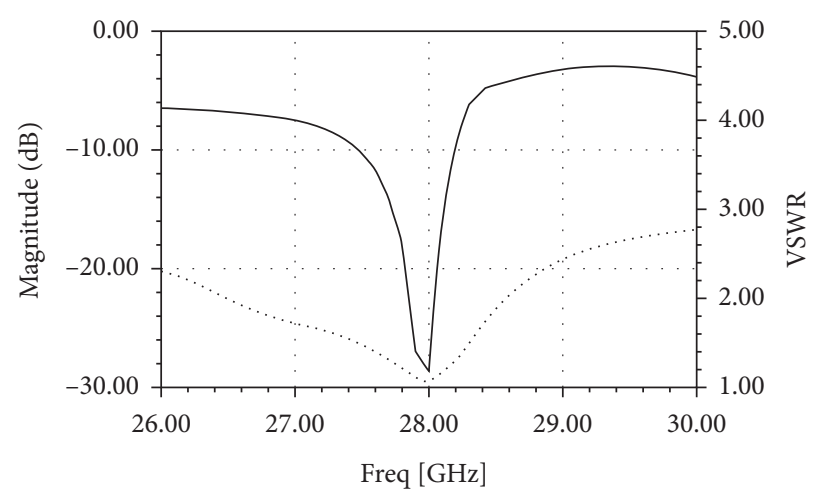

- Return Loss

..... VSWR

FIGURE 8: Proposed 34 elements thinned array antenna simulation results of return loss (S11) and VSWR.

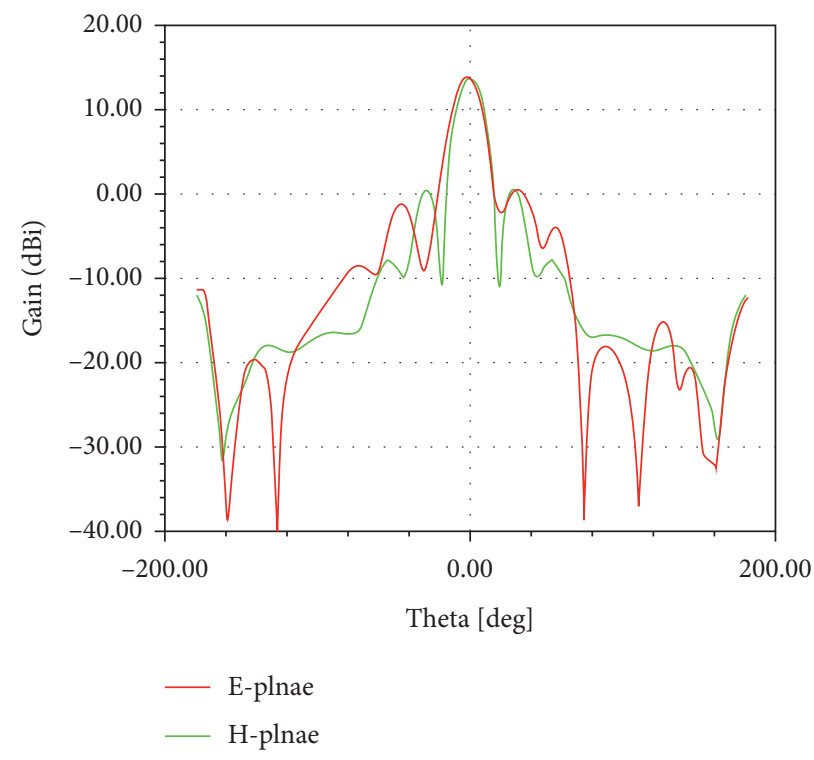

Figure 9: Proposed 34 elements thinned array antenna radiation pattern in E-plane and H-plane in HFSS.

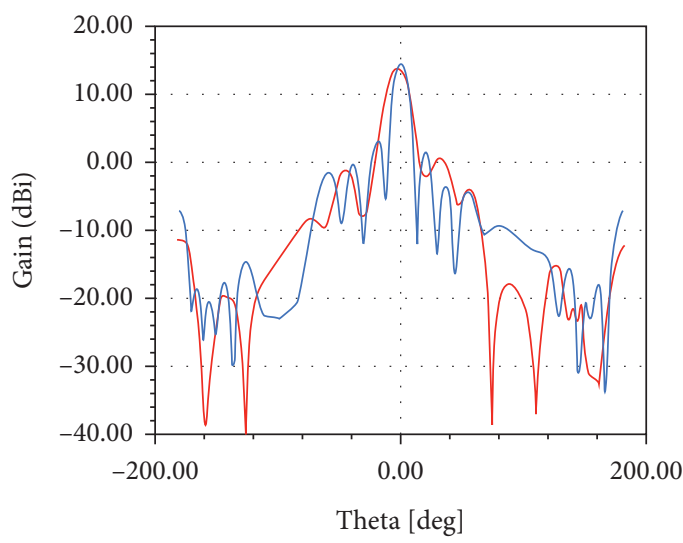

34 elements thinned array antenna

— $8 \times 8$ broadside uniform array antenna

(a)

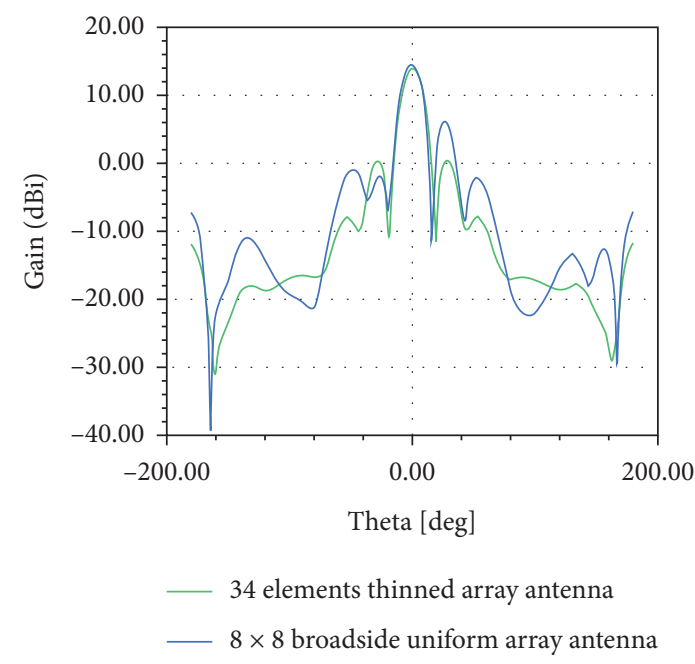

(b)

Figure 10: Comparison of radiation pattern between 34 elements thinned array antenna and $8 \times 8$ broadside uniform array antenna in Eplane (a) and H-plane (b). 


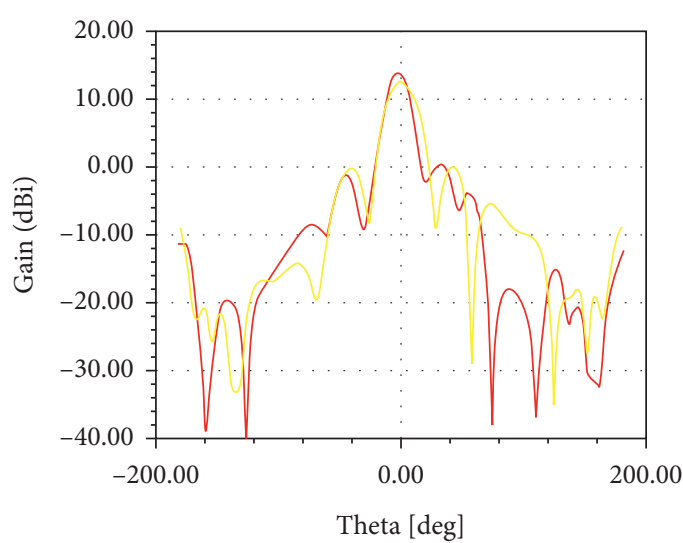

— 34 elements thinned array antenna

- $8 \times 4$ broadside uniform array antenna

(a)

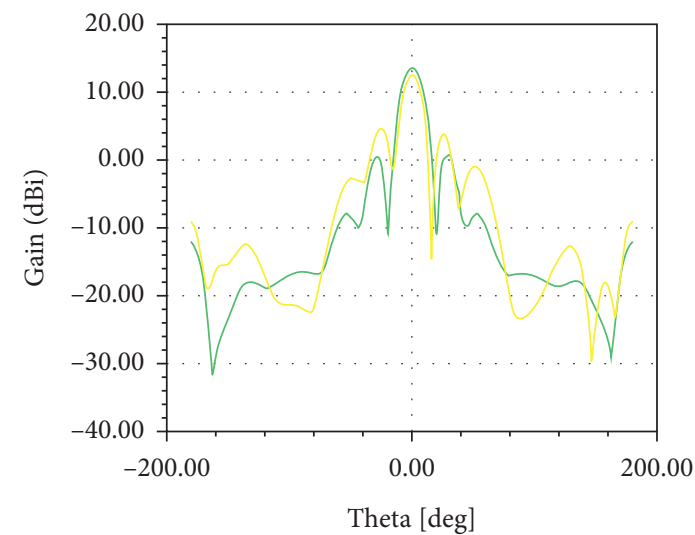

_ 34 elements thinned array antenna $8 \times 4$ broadside uniform array antenna

(b)

FIGURE 11: Comparison of radiation pattern between 34 elements thinned array antenna and $8 \times 4$ broadside uniform array antenna in Eplane (a) and H-plane (b).

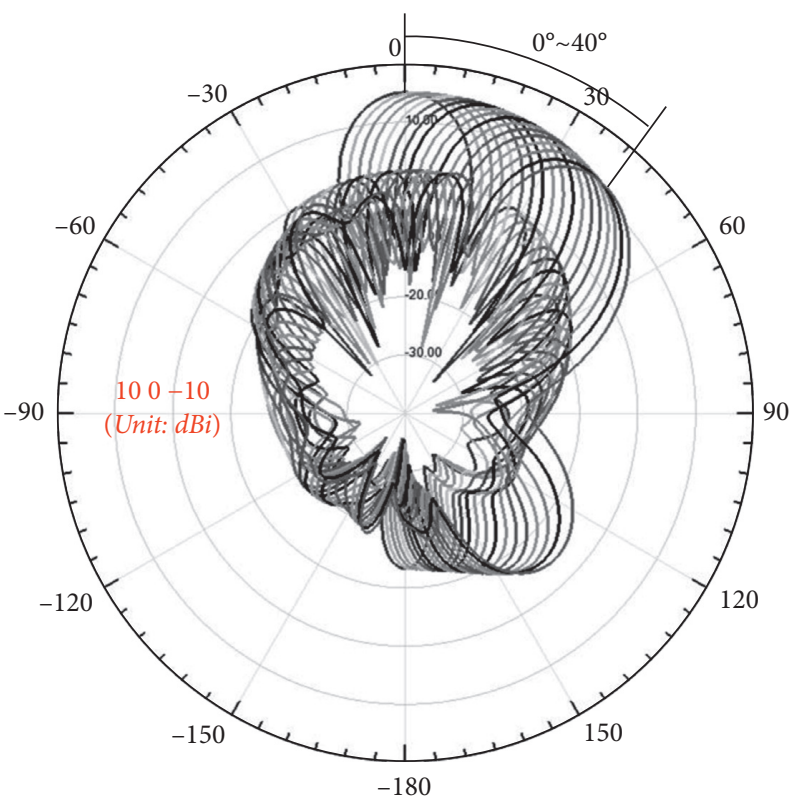

(a)

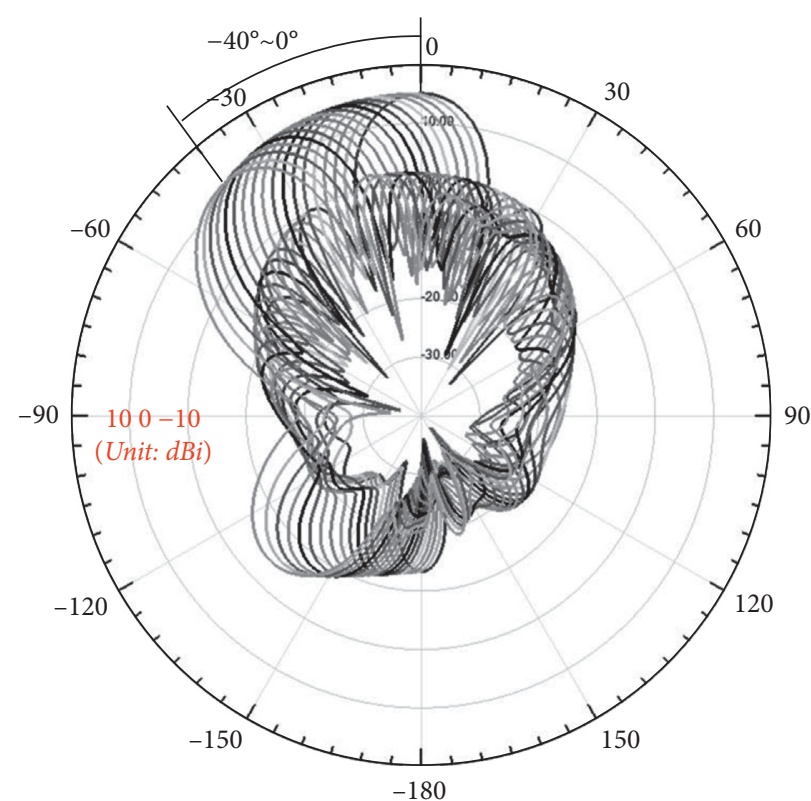

(b)

FIgURE 12: Proposed 34 elements thinned array antenna beam scanning angle range of $0^{\circ} \sim 40^{\circ}$ (a) and $-40^{\circ} \sim 0^{\circ}$ (b).

Therefore, it is concluded that after removing certain antenna elements, the array antenna maintains the beamforming characteristic, and the thinned array distribution has no effect on that.

3.2. Measurement Result of the Proposed 34 Elements Thinned Array Antenna. The proposed 34 elements thinned array antenna is fabricated inexpensively, and its photograph is shown in Figure 14. The proposed antenna is measured using Agilent E8351A network analyzer, and the comparison results of simulation and measurement return loss are demonstrated in Figure 15. The resonance frequency shift occurs between the simulated and measured results; it may be due to the fabrication tolerance on the copper etched, as well as the error of the dielectric constant of the used Fr-4 substrate at operating frequency. As there is no equipment for measuring the radiation pattern in our laboratory, the radiation performance is not presented. 


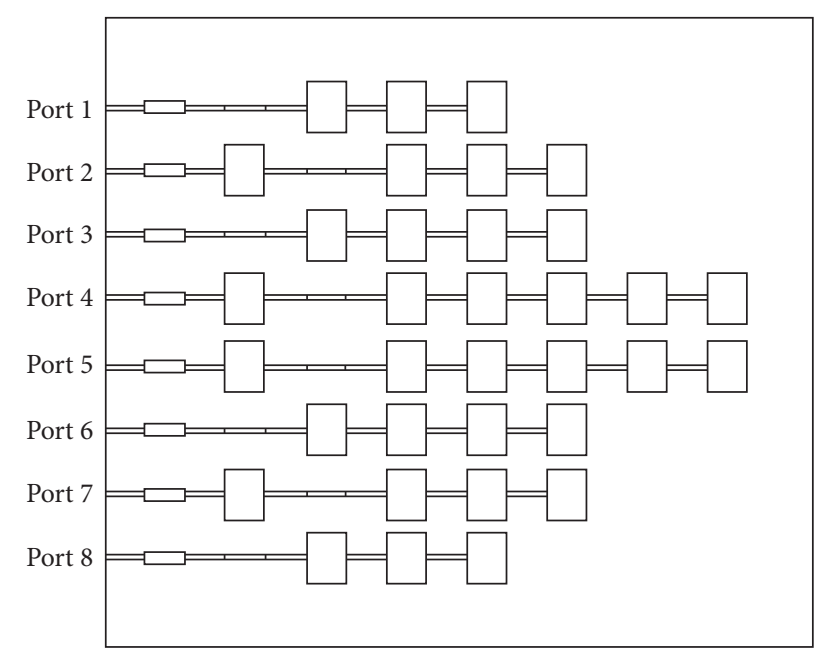

FIGURE 13: Ports setup for proposed 34 elements thinned array antenna.

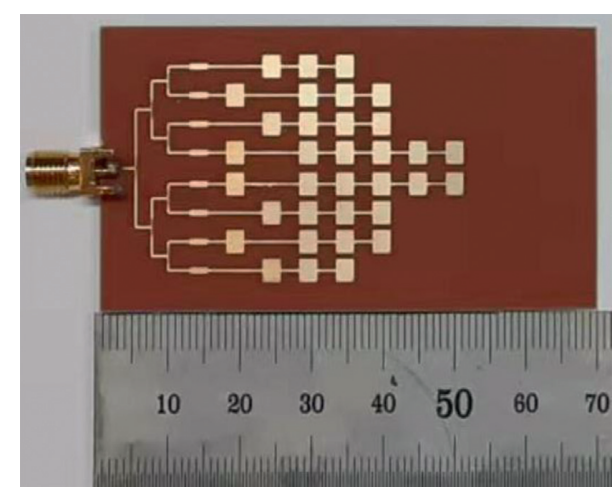

Figure 14: Photograph of fabricated 34 elements thinned array antenna.

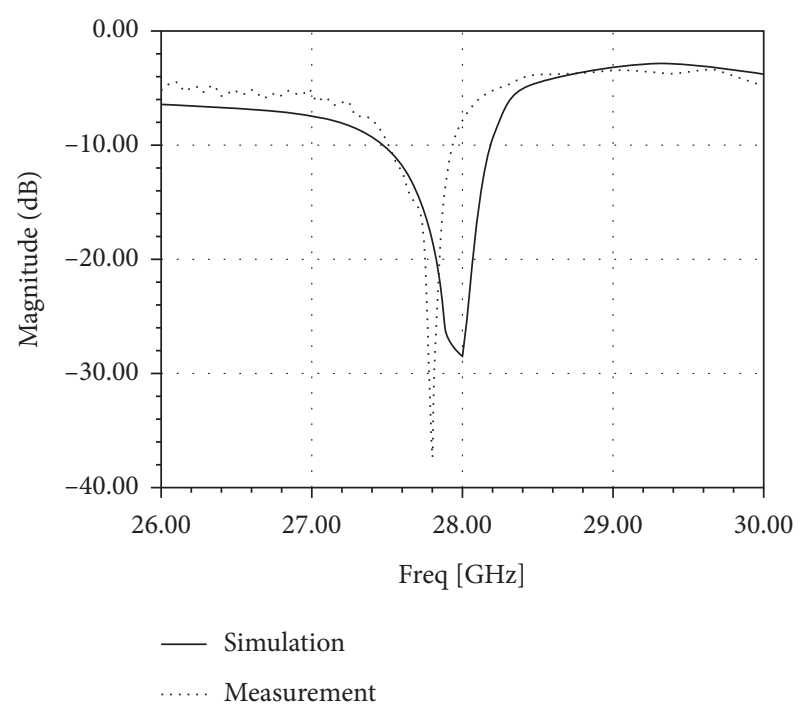

Figure 15: Comparison of simulation (solid line) and measurement (dotted line) return loss (S11) results.

\section{Conclusion}

In this thesis, a novel thinned array antenna is presented for $5 \mathrm{G}$ wireless applications, and it provides good radiation pattern at $28 \mathrm{GHz}$. The proposed 34 elements thinned array antenna shows good performance in terms of side lobe suppression. By comparing with $8 \times 8$ broadside uniform array antenna, though the gain is just $1 \mathrm{dBi}$ lower than that, the maximum side lobes (MSL) are $3.1 \mathrm{dBi}$ and $5.7 \mathrm{dBi}$ lower than the comparative $8 \times 8$ uniform array antenna in E-plane and H-plane, respectively. By comparing with $8 \times 4$ broadside uniform array antenna, the gain is $1.2 \mathrm{dBi}$ higher than that, and the MSL is $4.4 \mathrm{dBi}$ lower than the comparative uniform array antenna in $\mathrm{H}$-plane, though the MSL is just $0.5 \mathrm{dBi}$ higher in E-plane.

To reduce the manufactured cost of PCB, all the mentioned array antennas are designed on the $\mathrm{Fr}-4$ substrate, which has the thickness of $0.2 \mathrm{~mm}$, dielectric constant of 4.2 , and loss tangent of 0.02 . The measured resonant frequency of the proposed 34 elements thinned array antenna shows slightly shift down from $28 \mathrm{Ghz}$ by $0.2 \mathrm{GHz}$ that can be considered due to the fabrication tolerance of the copper etched as well as the error of the dielectric constant at operating frequency.

\section{Data Availability}

The simulation model data used to support the findings of this study are included within the article.

\section{Conflicts of Interest}

The authors declare that they have no conflicts of interest in this work.

\section{References}

[1] W. Roberts, L. Xu, J. Li, and P. Stoica, "Sparse antenna array design for MIMO active sensing applications," IEEE Transactions on Antennas and Propagation, vol. 59, no. 3, pp. 846-858, 2011.

[2] D. Pinchera, M. D. Migliore, and G. Panariello, "Synthesis of large sparse arrays using IDEA (inflating-deflating exploration algorithm)," IEEE Transactions on Antennas and Propagation, vol. 66, no. 9, pp. 4658-4668, 2018.

[3] D. Dai, M. Yao, H. Ma, W. Jin, and F. Zhang, "An asymmetric mapping method for the synthesis of sparse planar arrays," IEEE Antennas and Wireless Propagation Letters, vol. 17, no. 1, pp. 70-73, 2018.

[4] H. Liu, H. Zhao, W. Li, and B. Liu, "Synthesis of sparse planar arrays using matrix mapping and differential evolution," IEEE Antennas and Wireless Propagation Letters, vol. 15, pp. 1905-1908, 2016.

[5] M. B. Hawes and W. Liu, "Location optimization of robust sparse antenna arrays with physical size constraint," IEEE Antennas and Wireless Propagation Letters, vol. 11, pp. 1303-1306, 2012.

[6] L. F. Yepes, D. H. Covarrubias, M. A. Alonso, and R. Ferrús, "Hybrid sparse linear array synthesis applied to phased antenna arrays," IEEE Antennas and Wireless Propagation Letters, vol. 13, pp. 185-188, 2014. 
[7] R.-Q. Wang and Y.-C. Jiao, "Synthesis of sparse linear arrays with reduced excitation control numbers using a hybrid cuckoo search algorithm with convex programming," IEEE Antennas and Wireless Propagation Letters, vol. 19, no. 3, pp. 428-432, 2020.

[8] G. Prisco and M. D'Urso, "Maximally sparse arrays via sequential convex optimizations," IEEE Antennas and Wireless Propagation Letters, vol. 11, pp. 192-195, 2012.

[9] P. Angeletti, G. Toso, and G. Ruggerini, "Array antennas with jointly optimized elements positions and dimensions Part II: planar circular arrays," IEEE Transactions on Antennas and Propagation, vol. 62, no. 4, pp. 1627-1639, 2014.

[10] M. D’Urso, G. Prisco, and R. M. Tumolo, “Maximally sparse, steerable, and nonsuperdirective array antennas via convex optimizations," IEEE Transactions on Antennas and Propagation, vol. 64, no. 9, pp. 3840-3849, 2016.

[11] W. Zhang, L. Li, and F. Li, "Reducing the number of elements in linear and planar antenna arrays with sparseness constrained optimization," IEEE Transactions on Antennas and Propagation, vol. 59, no. 8, pp. 3106-3111, 2011.

[12] Z. Lin, W. Jia, M. Yao, and L. Hao, "Synthesis of sparse linear arrays using vector mapping and simultaneous perturbation stochastic approximation," IEEE Antennas and Wireless Propagation Letters, vol. 11, pp. 220-223, 2012.

[13] K. Chen, X. Yun, Z. He, and C. Han, "Synthesis of sparse planar arrays using modified real genetic algorithm," IEEE Transactions on Antennas and Propagation, vol. 55, no. 4, pp. 1067-1073, 2007.

[14] D. Pinchera, M. D. Migliore, F. Schettino, M. Lucido, and G. Panariello, "An effective compressed-sensing inspired deterministic algorithm for sparse array synthesis," IEEE Transactions on Antennas and Propagation, vol. 66, no. 1, pp. 149-159, 2018.

[15] S. K. Goudos, K. Siakavara, T. Samaras, E. E. Vafiadis, and J. N. Sahalos, "Sparse linear array synthesis with multiple constraints using differential evolution with strategy adaptation," IEEE Antennas and Wireless Propagation Letters, vol. 10, pp. 670-673, 2011.

[16] K. Chen, H. Chen, L. Wang, and H. Wu, "Modified real GA for the synthesis of sparse planar circular arrays," IEEE Antennas and Wireless Propagation Letters, vol. 15, pp. 274-277, 2016.

[17] A. Camps, F. Torres, I. Corbella, J. Bará, and P. de Paco, "Mutual coupling effect on antenna radiation pattern: an experimental study applied to interferometric radiometers," Radio Science, vol. 33, no. 6, pp. 1543-1552, 1998.

[18] H. J. Visser, Array and Phased Array Antenna Basicspp. 161-169, John Wiley \& Sons, Hoboken, NJ, USA, 3rd edition, 2005.

[19] C. A. Balanis, Antenna Theory:Analysis and Designpp. 283-297, John Wiley \& Sons, Hoboken, NJ, USA, 3rd edition, 2005. 